\title{
圈/ QUEEN'S UNIVERSITY BELFAST

\section{Understanding the psycho-social context for a new early intervention for resistance to change that aims to strike a beneficial balance between structure and flexibility}

Blackwell, S., Zylberberg, A., Scerif, G., Miller, S., \& Woodcock, K. A. (2021). Understanding the psycho-social context for a new early intervention for resistance to change that aims to strike a beneficial balance between structure and flexibility. BMC Psychiatry, 21(1), [621]. https://doi.org/10.1186/s12888-021-03519-1

\section{Published in:}

BMC Psychiatry

\section{Document Version:}

Publisher's PDF, also known as Version of record

\section{Queen's University Belfast - Research Portal:}

Link to publication record in Queen's University Belfast Research Portal

\section{Publisher rights}

(c) 2021 The Authors.

This is an open access article published under a Creative Commons Attribution License (https://creativecommons.org/licenses/by/4.0/), which permits unrestricted use, distribution and reproduction in any medium, provided the author and source are cited.

\section{General rights}

Copyright for the publications made accessible via the Queen's University Belfast Research Portal is retained by the author(s) and / or other copyright owners and it is a condition of accessing these publications that users recognise and abide by the legal requirements associated with these rights.

Take down policy

The Research Portal is Queen's institutional repository that provides access to Queen's research output. Every effort has been made to ensure that content in the Research Portal does not infringe any person's rights, or applicable UK laws. If you discover content in the Research Portal that you believe breaches copyright or violates any law, please contact openaccess@qub.ac.uk. 


\title{
Understanding the psycho-social context for a new early intervention for resistance to change that aims to strike a beneficial balance between structure and flexibility
}

Siobhan Blackwell ${ }^{1}$, Alex Zylberberg ${ }^{1}$, Gaia Scerif ${ }^{2}$, Sarah Miller ${ }^{3}$ and Kate A. Woodcock ${ }^{1 *}$ (D)

\begin{abstract}
Background: Emotional and behavioural problems linked to changes to expectations - resistance to change - are linked to disability in neurodevelopmental disorders, including autism spectrum disorder (ASD), Prader-Willi (PWS) and fragile $X$ syndromes (FXS). Structuring routines is best practice for minimising current resistance to change. But complete structure is impractical and flexibility in early life may actually reduce later resistance by supporting cognitive development. We aimed to examine the psycho-social context of families with children at risk of developing resistance to change so as to identify design requirements for an intervention that strikes a beneficial balance between structure and flexibility.

Methods: Thirty-six caregivers of children aged 4-12 years (17 ASD, 15 PWS, and 4 FXS) took part in an interview designed collaboratively with 12 professional stakeholders.

Results: Children need to feel like they are in control of flexibility but they also need support in choice making, understanding plans (using individually tailored visuals) and anxiety reduction. Caregivers need an accessible approach that they have full control over, and which they can tailor for their child. Caregivers also need clear guidance, education and support around structure and flexibility.

Conclusions: We propose a digital approach which addresses the needs identified. It tackles the most perplexing challenge by presenting flexibility to children in the context of a game that children can feel they have full control over, whilst caregivers can maintain control in reality. Furthermore, individualised support for children and caregivers would be enabled.
\end{abstract}

Keywords: Resistance to change, Anxiety, Temper outbursts, Behavioural flexibility, Cognitive flexibility, Neurodevelopmental disorders, Digital intervention, Emotional outbursts

\footnotetext{
* Correspondence: papers@katewoodcock.com

'Centre for Applied Psychology, School of Psychology \& Institute for Mental Health, University of Birmingham, 52 Pritchatts Road, Edgbaston, Birmingham B15 2SA, UK

Full list of author information is available at the end of the article
}

(c) The Author(s). 2021 Open Access This article is licensed under a Creative Commons Attribution 4.0 International License, which permits use, sharing, adaptation, distribution and reproduction in any medium or format, as long as you give appropriate credit to the original author(s) and the source, provide a link to the Creative Commons licence, and indicate if changes were made. The images or other third party material in this article are included in the article's Creative Commons licence, unless indicated otherwise in a credit line to the material. If material is not included in the article's Creative Commons licence and your intended use is not permitted by statutory regulation or exceeds the permitted use, you will need to obtain permission directly from the copyright holder. To view a copy of this licence, visit http://creativecommons.org/licenses/by/4.0/ The Creative Commons Public Domain Dedication waiver (http://creativecommons.org/publicdomain/zero/1.0/) applies to the data made available in this article, unless otherwise stated in a credit line to the data. 


\section{Background}

Challenging behaviours in children with neurodevelopmental disorders (NDDs) are among the most burdensome aspects of such disorders. They exacerbate caregiver stress, which can lead to further negative outcomes [18, 22, 32], and negatively impact learning and development $[34,40]$.

Resistance to change, which we define as the negative emotional and behavioural responses to altered routines, plans or expectations [33], is a common pathway to challenging behaviours in individuals with several NDDs, including autism spectrum disorder (ASD), Prader-Willi (PWS), and fragile X syndromes (FXS) [1,51]. Deficits in cognitive flexibility have been linked to such resistance to change in ASD [31], PWS and FXS [52]. Specifically, changes to expectations may place demands on deficient cognitive resources to precipitate challenging behaviour [53].

Importantly, it appears that sufficient flexibility in early childhood may be associated with appropriate development of cognitive flexibility, and the ability to deal with change. Specifically, increased exposure to particular routines has been associated with increased resistance following changes to those routines [6]. Furthermore, exposure to more varied environments has been linked to better cognitive flexibility in early childhood [2]. And more rigid routines at this age have been associated with more resistance to change later in life [19]. Thus, an approach that supports families to expose children to sufficient flexibility in routines and environments may constitute an effective early intervention for resistance to change. Early interventions are crucial in optimising developmental outcomes and improving caregiver wellbeing (NICE clinical guideline 170, 2013 [35]). Yet, no existing early interventions specifically target resistance to change and systematic reviews suggest that existing early interventions for challenging behaviours are not effective in preventing resistance to change [21].

Current best practice around managing change-related behaviours focuses on structuring environments to increase predictability, thus avoiding change (NICE clinical guideline 170, 2013 [30, 45];). However, it is pragmatically impossible to avoid all change, as illustrated by the need for visual change signalling strategies [5, 45]. Furthermore, there is no available data on the long term outcomes of an early-life structuring approach. Critically, such approaches in their current form directly oppose the potential benefit that may be linked to early life exposure to sufficient environmental flexibility.

When considering the development of a new early intervention, it is relevant that parent-mediated approaches can reduce the demand on professional services, and can be linked to positive long-term outcomes [41]. However, challenges to fidelity and implementation often limit efficacy $[46,49]$. Furthermore, a notable disconnect has been identified between intervention efficacy (how well it works in optimal, closely controlled circumstances) and intervention effectiveness (the magnitude of its associated beneficial effects in real life conditions). Indeed, these two criteria for intervention success have been posited as incorporating certain diametrically opposing characteristics [15]. Thus, several approaches to complex intervention development have been conceptualised and implemented with a view to minimising research wastage and maximising the likelihood that an intervention developed will be taken up and have a beneficial impact on the population it was designed to support [28]. A comprehensive systematic review has examined these intervention development approaches and concluded that there is insufficient evidence at present to suggest that one single approach or one type of approaches is more effective than another [38]. However, a number of features of intervention development are common across multiple approaches, and certain approaches appear particularly suitable for specific settings, populations or intervention goals [37].

Two features of intervention development that have been gleaned from multiple approaches are involvement of stakeholders and ascertainment of primary empirical data to understand the context in which an intervention will operate [37]. These features are particularly prominent in what have been taxonomised as Partnership and Target Population Centred approaches to intervention design respectively [38]. Both of these approaches ultimately build and evolve the development process in response to relevant stakeholders' needs, perspectives and wishes (the approaches are primarily distinguished by the distribution of decision making responsibility across researchers and stakeholders). Being sensitive to individual needs has been identified as a priority with respect to interventions for people with neurodevelopmental disorders [49], and working collaboratively with stakeholders allows an in-depth understanding of individuals' needs to take precedent [54]. Thus, our approach to intervention development sits at the boundary between Partnership and Target Population Centred categories and incorporates extensive collaboration with stakeholders.

It has been recognised that in rigorous and useful intervention design work, it may be necessary to conduct multiple pieces of research, which need to be reported separately [37]. Here, we report on the first stage of our intervention development process, in which we collaborated with stakeholders in order to understand the psycho-social context of a parent-led early intervention aiming to expose children with neurodevelopmental disorders to flexibility in their routines early in life, whilst maintaining enough structure to remain in line with current best practice. We aimed to examine this psychosocial context in order to propose intervention design requirements, which would form the basis of a design 
prototype, to be iteratively refined in the next stage of the development process in further collaboration with stakeholders.

\section{Methods \\ Participants}

Thirty-six families were recruited through family support organisations in the UK. Families of children with ASD, PWS, and/or FXS between 4 and 12 years were eligible. For Prader-Willi and fragile $\mathrm{X}$ syndromes, we recruited via the Prader-Willi Association UK and the Fragile X Society, which are the only UK wide family support associations for these syndromes. For autism spectrum disorder we recruited via UK wide and local support organisations. Recruitment advertisements were made available via websites and social media to all members of the recruiting organisations. Adverts explained that the research team was looking for parents with an interest in helping to develop a new strategy to prevent children from developing difficulties with change. Our goal was to develop an early intervention approach targeting 4-6 year olds as this is the period that has been highlighted as particularly pertinent to the development of cognitive flexibility in this context. However, since difficulties with change often increase over the primary school period, we included families with children up to 12 years to ensure that we included the perspective of families already experiencing substantial difficulties with change. This was critical since we anticipated that current experience of difficulties with change would be an important potential barrier to engagement with an intervention developed. Ethical approval was granted by the University of Birmingham Ethical Review Committee (ERN 17-0923, 09/01/2018) and informed consent procedures implemented accordingly. A professional advisory network $(n=12)$ was recruited via established relationships with the research team and provided feedback throughout the research process, including on design, research conduct and interpretation of results. Members of the advisory network included senior managers of early intervention services, teachers, specialist physicians, a speech and language therapist, a clinical psychologist, applied behaviour analysts, and parents with additional relevant professional experience. All members had experience with ASD, all but two had experience with learning disability, four had experience with PWS and one had experience with FXS (see Appendix A.1).

\section{Measures}

\section{Development of a semi-structured interview schedule}

An informant-report interview schedule was developed in collaboration with the advisory network to examine psycho-social contextual factors relevant to the proposed early intervention. A draft of the interview schedule was prepared by the research team with a view to incorporating presentation of appropriate information about the goals of the interview (to gather information on participating families' ongoing and prior experiences that would be potentially relevant for the development of an early intervention approach that aims to increase the flexibility in young children's routines). In line with individual and systemic factors having been identified as influencing intervention implementation fidelity [3], questions that would allow caregivers to describe current and previous experiences with their child's routines, flexibility, associated behaviours and communication were incorporated alongside questions aiming to elucidate parents' feelings of self-efficacy around increasing flexibility and their feelings on the support they receive in caring for their child. Furthermore, questions around behaviour management strategies that families were currently or had previously implemented, were designed to inform on the strengths and limitations of existing evidence based strategies (e.g. [20, 24]).

Six individual or group discussions, each with between one and three advisory network members provided feedback on the draft schedule. Developments of the schedule in response to the feedback included a general refinement of wording to make it more concrete and addition of prompting for anecdotes to explicate points being made. Furthermore, concrete bench marking systems for describing certain aspects of children's individual characteristics were introduced (e.g. Hanen's communication stages, level of cognitive impairment as described in children's Education Health Care Plans). Questions around current use of behaviour management strategies were expanded to explore families' fidelity to and understanding of these. Questions around flexibility were also expanded to explore reasons why caregivers may be resistant to implementing this. Finally, prompts were added to explore other people's recognition of children's difficulties to provide further context to parents' feelings of support.

Following refinement of the schedule, advisory group members were asked to rate their opinion on its appropriateness for ascertaining the necessary information on the psycho-social context of the planned early intervention to facilitate its development (using a 5-point Likerttype scale from strongly disagree to strongly agree). Consensus was reached, with all advisors agreeing or strongly agreeing that the schedule was appropriate - a criterion that has been applied previously in the development of complex interventions in collaboration with professional stakeholders [26].

The final schedule was piloted with two parents of children with a neurodevelopmental disorder diagnosis (FXS, aged 4 years; ASD, aged 6 years). At this stage, 
three questionnaire measures, which were required to formally characterise children for the purpose of the future planned testing in the wider intervention development study, were administered verbally at the beginning of the interview. The questionnaires included the impact supplement of the Strengths and Difficulties Questionnaire (SDQ [16];) the Behavior Flexibility Rating ScaleRevised (BFRS-R [17];) and the switch subscale of the Behavior Rating inventory of Executive Functioning (BRIEF [14];). The pilot interviews were recorded and members of the research team listened back to these. However, the only substantive refinements judged necessary were to remove the questionnaires and initial demographic questions on education setting from the interview schedule and instead administer these in online survey form prior to the interviews. Thus, the two pilot interviews were included in the primary analysis detailed below.

\section{Semi-structured interview}

The interview schedule included a total of 83, primarily open ended questions. These covered the child's background characteristics, their preference for routine, current routines and factors influencing their ability to deal with changes to routines, and behaviours linked to such changes. Furthermore the family's experiences with use of visual schedules and intentionally implementing variability in routines, and the support received from others for any behaviour management strategies currently or previously in place. Finally, direct questions on opportunities and challenges for designing an intervention to increase flexibility in routines, including children's ability to choose flexible options (see Table 1 and Appendix B.1). Only relevant questions were asked of each respondent (e.g. some were only relevant to parents or teachers) and interviews were structured in the form of a discussion such that if questions had already been answered in a previous response, they were not asked again.

\section{Procedure}

Parents completed the questionnaires on the clinical impact of resistance to change, behavioural flexibility and cognitive flexibility (listed above), which were required to provide background information for the wider intervention development study via an online survey prior to taking part in the interview. As a part of this survey, 5 questions on educational setting were administered (type of school, number of children in class, type of support at school, educational support plans and level of academic functioning - see Appendix B.2). Interviews were administered via telephone or video conference with an average duration of $90 \mathrm{~min}$ (range $50-125 \mathrm{~min}$ ), and were audio recorded. For three families, the primary and secondary caregiver were interviewed together.

\section{Analysis}

The first author reviewed audio recordings, documented responses for subsequent analysis, and transcribed illustrative quotes [51]. A second researcher reviewed files for accuracy, disagreements were discussed, and agreement was reached. The first author has experience in administering behaviour interventions in an earlyintervention setting which potentially informed data collection and analysis [36].

Content analysis was applied inductively to operationally define codes from which to derive design requirements

Table 1 Summary of semi-structured interview schedule, for full interview schedule, see Appendix B

\begin{tabular}{|c|c|c|}
\hline Topic & $\begin{array}{l}\text { Number of } \\
\text { questions }\end{array}$ & Primary issues addressed \\
\hline Child's background & 10 & $\begin{array}{l}\text { Basic demographics, level of cognitive ability in relation to scheduling \& choice making, } \\
\text { communication level }\end{array}$ \\
\hline Preference for routine & 6 & $\begin{array}{l}\text { Previous and current ability of child to deal with change, parent's approach to structuring routines, } \\
\text { advice received relevant to routines and how far this was followed }\end{array}$ \\
\hline Use of visuals & 8 & $\begin{array}{l}\text { Current use of visuals including consistency of use, parental confidence in use, limitations } \\
\text { experienced and child's preferred modalities }\end{array}$ \\
\hline $\begin{array}{l}\text { Routine \& change in a typical } \\
\text { day }\end{array}$ & 12 & $\begin{array}{l}\text { Walk through a typical day, high and low risk times for child stress, more and less tolerated } \\
\text { changes, influence of parents and others on child's response, use of specific techniques to } \\
\text { manage change }\end{array}$ \\
\hline $\begin{array}{l}\text { Experience with implementing } \\
\text { flexibility }\end{array}$ & 12 & $\begin{array}{l}\text { Previous experience of intentionally increasing variability in routines including procedure used, } \\
\text { reasons for doing this, challenges and outcomes }\end{array}$ \\
\hline Behaviours linked to changes & 5 & Type, duration and frequency of behaviours shown by child in response to changes \\
\hline $\begin{array}{l}\text { Support with family } \\
\text { management of behaviours }\end{array}$ & 7 & $\begin{array}{l}\text { Involvement of family members, school and other professionals in strategies that have been } \\
\text { implemented by parents for the management of children's behaviour }\end{array}$ \\
\hline Intervention design & 23 & $\begin{array}{l}\text { General anticipated challenges with increasing flexibility and how to avoid these, communication } \\
\text { of and content of plans, integrating choice and flexibility into plans, motivation for flexibility, } \\
\text { necessary support for parents and others }\end{array}$ \\
\hline
\end{tabular}


[12]. Analysis was descriptive as the focus was on understanding experiences. Importantly, in line with the ethos of human centred design practices, with which our intervention development approach are closely aligned, even single voices that highlight a potential barrier to implementation have important implications for design requirements - requirements should accommodate the needs of all potential users [11]. Thus, no minimum frequency criterion was imposed for deeming that a code was relevant for extraction. Rather, all information relevant to design requirements was extracted and operationally coded.

A second reviewer independently classified responses for the presence or absence of the operationally defined codes. Inter-rater reliability was assessed using Cohen's kappa [8]. Initially, $1.5 \%$ of codes evidenced almost perfect agreement $(0.81-1.00), 5.9 \%$ substantial agreement (0.61-0.80), 22.1\% moderate agreement (0.41-0.60), $30.9 \%$ fair agreement $(0.21-0.40)$ and $39.7 \%$ less than fair agreement. Operational definitions of codes were refined via discussion across 4 sessions $(20 \mathrm{~h})$ and where unambiguity in the definition could not be reached, the code was dropped. Final Kappa values ranged between 0.811.00 , indicating almost perfect agreement [29] for the 68 resultant codes (see Appendix $\mathrm{C}$ for operational definitions).

Codes were discussed amongst the research team, which included a systems design engineer, a researcher with practical experience of implementing and managing early intervention behavioural services for autistic children, and a researcher with experience of discussing behaviour with the family members of children with neurodevelopmental disorders and of psychological intervention design and evaluation. Codes were clustered into higher level themes, which incorporated the individual variability evidenced across codes. The proportion of parents reporting a particular code was considered in this clustering process, but in line with human-centred design practices, minority voices were also considered carefully, particularly where these represent specific design challenges or opportunities that would otherwise be missed. Themes were further reviewed alongside their constituent codes. Groups of one or more themes were then drawn together with the research team's knowledge of the theoretically driven objectives for the early intervention and of the full interview context from which the codes were derived, to create specific design requirements. We acknowledge that other research teams with differing collective experience may derive different design requirements from the codes. Our focus was therefore on transparency of analysis, which we have used to inform our own intervention design with the present design requirements, but which others may use to inform further research and practice in other ways as they see fit.

\section{Results}

\section{Population characteristics}

Mean child age was 7.8 years $(S D=2.2)$ and mean age of diagnosis varied across disorders (PWS: $1.28 \mathrm{M}$, FXS: 2.08y, ASD: $5.79 y)$. Most children were in mainstream school (72\%), had an Education and Health Care Plan (52.8\%) and communicated verbally through sentences (all but 2). Two children were on prolonged absence from mainstream school (see Appendix D, Tables D.1 \& D.2).

Most households were two-parented, half of which held an occupation indicative of a higher socio-economic status [48]. Eighty-nine percent were caring for other children. Sixty-one percent reported that previously used strategies for change-related difficulties were ineffective. Sixty-seven percent reported that such strategies were applied inconsistently (see Appendix D, Table D.3).

\section{Design requirements}

Interview codes, concomitant themes and design requirements are described in Table 2. Seven design requirements were generated, which can be loosely grouped into four areas: the general context of the intervention, communication, implementation and anxiety management.

\section{General context}

(1) First, in terms of the general context of the intervention, the most commonly received professional advice was to impose structure on routines (though still reported by less than half of parents). Furthermore, only a small minority of parents were advised to include variation in structures and only just over half of parents reported that any professional advice received had been useful in managing challenging behaviour. Thus, we identified $a$ need for clear guidance on structure and flexibility.

(2) There were a number of reports from small groups of parents around specific ways of engaging with the child and how this is influenced by experience. These suggest that the history of the relationship between the child and their caregivers can influence how caregivers manage children's environments. Furthermore parents' background and experiences impacted on their willingness and ability to promote flexibility, suggesting that caregivers differ in how prepared they are to support flexibility. Direct suggestions from parents alongside parents' misapprehensions around some key concepts relevant to the planned intervention, also highlighted psycho-education for caregivers as being important. We therefore identified a need for integrated caregiver training and support for problem solving. 
Table 2 Design requirements (in bolded rows), contributing themes and interview codes. Codes are ordered by frequency of caregiver reports within each category, frequency of reporting and final Kappa inter-rater reliability are also shown

\begin{tabular}{llll}
\hline Theme & Code name & Kappa
\end{tabular}

Clear guidance on structure and flexibility is needed

Variation in professional advice on structure: Structuring routines predominated advice from professionals but varied across families and was not always useful.
Courses/professional advice is useful in managing challenging behaviours

Advised to create a structure or use visuals

No advice on routines received

Advised to vary structures
$1952.78 \quad 1$

$17 \quad 47.22 \quad 1$

$\begin{array}{lll}10 & 27.78 & 0.82\end{array}$

$4 \quad 11.11 \quad 1$

\section{Intervention should include caregiver training and support caregivers to solve problems around implementation}

Caregivers' experiences affect how they engage with the child: The history of the relationship between the child and their caregivers influences how caregivers manage the environment.

Caregivers differ in preparedness for supporting children's flexibility: Parents' background and experience impacts on their willingness and ability to promote flexibility.

Psycho-education for caregivers is important: Integrated support for caregivers, including education would facilitate implementation of the approach.
Siblings and peers used to encourage child's engagement

Parents treat child like a typically developing child

Improved parental management of changes with experience reduces the likelihood of resistance to change

Parents are willing to vary structures

Parent background and education contribute to understanding

Parents have learned strategies to deal with resistance to change outside targeted training/professional advice/ educational background

Parents are hesitant to intentionally vary routines

Parental self-efficacy influences ability to introduce flexibility

Caregiver supported problem solving should accompany the approach

Parents' understanding of cognitive processes underlying child's difficulties helps parents support their child more effectively

Parents incorrectly mistake transitions and task-completion as resistance to change

Psycho-education would help parents understand children's $\quad 4 \quad 11.11$ difficulties

Easy to follow reminders /prompts to implement the approach are suggested

Guidance in evaluating progress and triggers is suggested
$8 \quad 22.22 \quad 1$

$7 \quad 19.441$

$5 \quad 13.891$

2261.11

1233.331

$8 \quad 22.22$

$7 \quad 19.44 \quad 1$

$5 \quad 13.891$

2261.111

$8 \quad 22.22 \quad 1$

$7 \quad 19.44$

$4 \quad 11.11 \quad 1$

$1 \quad 2.78 \quad 1$

Intervention should support visual planning in way that is appealing to children and can be modified by caregivers to suit the family

A new approach to visuals is needed: A novel way of using visuals is needed to facilitate long term implementation and utility.

Families differ in preferences for structure: Structure to routines is sometimes necessary but the level of preferred structure in routines varies across caregiving families and across children.
(Traditional) visuals lose impact over time

$2055.56 \quad 1$

Visuals are important to support children using a new

1644.45 approach

Visuals increase rigidity

$5 \quad 13.891$

Visuals have practical disadvantages

411.111

Family structure enhances naturally occurring variability

$17 \quad 47.22 \quad 1$

Structure is originally driven by child's needs

$16 \quad 44.44 \quad 1$

Structure is necessary to meet practicalities of family life

$13 \quad 36.111$

Parents don't like rigid structure

$10 \quad 27.78 \quad 1$

Parent has a personal preference for structure

$8 \quad 22.22$

Child implements self-imposed routine

Flexibility should be imposed in a structured way where possibilities are planned in advance by caregivers and are communicated clearly to the child

Individuals differ in changes that are problematic: Specific types of
changes precipitate challenges, which vary across individuals but can be in expectations, order and/or people.
Child's expectations not being met is upsetting

1952.781

Parents are aware of the underlying causes of resistance to change
1130.561 
Table 2 Design requirements (in bolded rows), contributing themes and interview codes. Codes are ordered by frequency of caregiver reports within each category, frequency of reporting and final Kappa inter-rater reliability are also shown (Continued)

\begin{tabular}{|c|c|c|c|c|}
\hline Theme & Code name & $\mathrm{N}$ & $\%$ & Kappa \\
\hline & $\begin{array}{l}\text { Changes to fixated rules of order and duration of task/ } \\
\text { routines are problematic }\end{array}$ & 8 & 22.22 & 1 \\
\hline & Being in the presence of unexpected people is upsetting & 7 & 19.44 & 1 \\
\hline \multirow{7}{*}{$\begin{array}{l}\text { Communication is linked to resistance to change: Communication } \\
\text { between child and others can influence resistance to change } \\
\text { and how this develops over time. }\end{array}$} & $\begin{array}{l}\text { Child's management of unexpected change improved with } \\
\text { age }\end{array}$ & 15 & 41.67 & 1 \\
\hline & $\begin{array}{l}\text { Increased communication linked to reduced resistance to } \\
\text { change }\end{array}$ & 15 & 41.67 & 1 \\
\hline & $\begin{array}{l}\text { Child's management of unexpected change worsened with } \\
\text { age }\end{array}$ & 10 & 27.78 & 1 \\
\hline & No change in child's resistance to change with age & 4 & 11.11 & 1 \\
\hline & $\begin{array}{l}\text { Child's increased ability to communicate is linked with } \\
\text { increased resistance to change }\end{array}$ & 2 & 5.56 & 1 \\
\hline & $\begin{array}{l}\text { Child's own awareness of the need to be flexible has } \\
\text { increased with age }\end{array}$ & 2 & 5.56 & 1 \\
\hline & $\begin{array}{l}\text { Increased demands or expectations of what child should be } \\
\text { capable of doing with age affects behaviour }\end{array}$ & 3 & 8.33 & 1 \\
\hline
\end{tabular}

Intervention should incorporate game-like components, which give children perceived control over flexibility and support their choice making

A game-like approach would motivate flexibility: A game-like approach that incorporates reinforcement (delayed/ social) and perceived control (distancing this from primary caregivers) would motivate children's flexibility.
Support for choice making is necessary: Knowledge of practical alternative choices and support in selecting a choice would promote flexibility.
Delayed reinforcement is motivating

$15 \quad 41.67 \quad 1$

Unexpected change more tolerable if child perceives that they have some control/input over how it changes

Change is tolerable if more enticing

1130.561

Social praise is motivating

Game-like changes increase compliance

Change is more likely to be problematic when initiated by primary caregivers than non-primary caregivers

(Traditional) token economies/delayed reinforcement is not useful

Delayed reinforcement is contrived

1130.561

$\begin{array}{lll}11 & 30.56 & 0.94\end{array}$

1027.78

$6 \quad 16.67 \quad 1$

$6 \quad 16.671$

$2 \quad 5.56 \quad 1$

Child struggles with choice making and processing alternatives

Presenting alternatives is beneficial for preparing child for potential variation

Familiarity makes tolerating change more manageable

Varied choices are required to prevent fixations

2055.561

$16 \quad 44.44 \quad 1$

$925 \quad 1$

$4 \quad 11.11 \quad 1$

\section{Intervention should use technology to facilitate ease of access and adaptation to individual needs}

Technology should support access: A technology-assisted tool that is transportable and can be used flexibly would be beneficial.

Individual adaptation is beneficial: An approach that allows a child to experience achievement on an ongoing basis would be motivating.
Choices are impractical due to pressure they put on parents

Choices (with no preferential bias by child) are the most naturally occurring and convenient way to introduce flexibility

Technology as a convenient way of facilitating the approach $\quad \begin{array}{llll}13 & 36.11 & 1\end{array}$

Approach should be transportable across people and $4 \quad 11.11 \quad 1$ settings

Approach should not be prescriptive, there should be an ability to adapt features when needed

The approach should be designed to set the child up for success and generate initial buy-in

Feelings of achievement are motivating

$8.33 \quad 0.84$

$3 \quad 8.33 \quad 1$
$10 \quad 27.78 \quad 1$

$6 \quad 16.67 \quad 1$

513.891

$2 \quad 5.56 \quad 1$ 
Table 2 Design requirements (in bolded rows), contributing themes and interview codes. Codes are ordered by frequency of caregiver reports within each category, frequency of reporting and final Kappa inter-rater reliability are also shown (Continued)

\begin{tabular}{|c|c|c|c|c|}
\hline Theme & Code name & $\mathbf{N}$ & $\%$ & Kappa \\
\hline \multicolumn{5}{|c|}{ Intervention should support management of children's anxiety around change } \\
\hline \multirow{6}{*}{$\begin{array}{l}\text { Children's emotions impact intervention needs: Children's anxiety } \\
\text { around change limits flexibility - support for managing anxiety } \\
\text { is important }\end{array}$} & Child needs a chance to process the change & 13 & 36.11 & 0.95 \\
\hline & Child masks difficulties throughout day & 13 & 36.11 & 0.95 \\
\hline & Change more tolerable if child feels safe & 9 & 25 & 0.94 \\
\hline & $\begin{array}{l}\text { Caregivers reduce warning to avoid the build-up of } \\
\text { anticipation anxiety }\end{array}$ & 6 & 16.67 & 1 \\
\hline & Child struggles to identify emotions & 6 & 16.67 & 1 \\
\hline & $\begin{array}{l}\text { Techniques needed to reduce rumination and anxiety for } \\
\text { child prior to change }\end{array}$ & 2 & 5.56 & 1 \\
\hline
\end{tabular}

\section{Communication}

(3) In terms of communication, just under half of parents identified visuals as important to support children's use of a new approach. However, over half reported that visuals lose impact over time and a number of specific disadvantages of visuals were identified by important sub-groups of parents. Thus, a novel way of using visuals is needed. Furthermore, a number of codes converged to suggest that whilst structure to routines can be necessary, the level of structure varies depending on the family. These codes included the preferred level of structure varying across families, and structure linking to children's needs and parental preferences in substantial sub-groups of respondents. We therefore identified a need for visual planning that is appealing to children and can be modified to suit the family.

(4) Several specific types of changes were identified that were challenging for children, each was identified in a sub-group of children, meaning that the specific types of changes that are challenging vary across individuals. However, in general changes were potentially problematic for the majority of children. Furthermore, several codes linked communication to children's resistance to change. A number of different relationships were identified in different sub-groups of children, but it was clear that communication between the child and others can influence how resistance to change develops over time. Thus, we identified a need for flexibility to be imposed in a structured way where possibilities are planned in advance by caregivers and communicated clearly to children.

\section{Implementation}

(5) In terms of practical implementation, increased compliance with change and increased motivation was linked to the kinds of reinforcement systems integral in games (enticing game-like events, delayed reinforcement, social reinforcement). Importantly, increased compliance was also linked to children having perceived control over their actions. However, reports of children struggling with choice making by more than half of respondents, and advantages of presenting children with alternatives, suggested that support for choice making is needed. Thus, we identified the need for game-like intervention components that give children perceived control over flexibility and support their choice making.

(6) Parents provided specific suggestions around the potential benefit of a technology-mediated approach and a need for the approach to be transportable across settings. Furthermore, a number of codes highlighted the importance of individual adaptation for example to increase initial buy-in and motivation. Thus, we identified a need for a technology-assisted approach that makes access easy and adapts to individual needs.

\section{Anxiety management}

(7) Finally, the importance of the management of anxiety around changes was highlighted in several ways by sub-groups of parents. For example, more than a third of respondents reported that children needed time to process changes and that they mask difficulties they experience during the day (i.e. anxiety build up). Furthermore, a quarter of parents reported that children find changes more tolerable if they are feeling safe. Thus, we identified a need to support the management of children's anxiety around change.

\section{Discussion}

We interviewed the caregivers of children with a diagnosis of PWS, FXS or autism (at risk of developing resistance to change), to better understand the psycho-social context of a new early intervention aiming to increase flexibility in young children's routines in a manner that 
is structured enough to be in keeping with best practice and minimise any currently experienced difficulties with change. From this understanding of the psycho-social context, we aimed to develop design requirements for the proposed early intervention, which we hypothesise will ultimately reduce the development of resistance to change. Below we discuss how these design requirements informed the specifications of an initial design prototype for the proposed early intervention, which is being further developed in collaboration with stakeholders in ongoing research. It is relevant to highlight that although some of the design requirements identified are consistent with prior knowledge about families' needs, without the present research it would not have been possible to identify which needs from a wide range pointed towards in the literature, would be important for the present intervention. Furthermore other needs identified (e.g. need for children to have perceived control) are consistent with working knowledge held by some practitioners, for example members of our professional advisory network. However, the relevance of this knowledge could not have been anticipated prior to this research. Thus, the present results of our collaborative development of knowledge are consistent with the previously discussed benefits of stakeholder engagement in intervention development [37].

To inform on how to facilitate a balance between structure and flexibility at a practical level, the most relevant design requirement (5) anticipates the utility of including game-like components in the intervention, which give children the perception of control over the flexibility imposed and support children's choice making. In our experience, anecdotal caregiver reports of improved compliance when children feel like they are in control are common, and this is consistent with an individual being asked to do something they don't want to do constituting a common trigger of emotional outbursts [42]. Furthermore, we have previously described difficulties in complex decision making in autistic adolescents and suggested that atypical emotion regulation may be linked to increased negative emotional experience during such decisions [50]. This suggests that support for choice making may help to minimise children's negative emotional experience around imposed flexibility. To address these issues, the core of our design prototype specification involves a mechanism designed to be perceived as a game by a child. It is the spin of a wheel in the game - which is, unbeknown to the child, controlled by the caregiver - that determines how flexible a child's routine needs to be. To satisfy the child's need for control, the child has full control over spinning the wheel. However, to support choice making, the wheel spin determines which of a number of alternative ways of engaging in a routine is imposed.
Another design requirement fundamental for practical implementation is the need for visual planning that is appealing to children and can be modified to suit the family (3). Despite being widely used, the limited empirical research on visual schedules has tended to report on single case series. Benefits have been highlighted but in such designs, visuals have been created in different ways for each individual [27]. Incorporating visuals that allow caregivers to plan multiple distinct available alternatives and communicate these to children in order to scaffold flexibility, is consistent with applied-behaviour-analysisbased techniques around use of visuals to facilitate selforientation and task-processing - having visual cues for all potential alternatives provides additional processing time, which may be necessary in the context of the specific cognitive challenges experienced by children (e.g. [24]). Furthermore, visual depictions of alternatives can be reliably paired with specific upcoming events, and such stimulus-response training can increase predictability - facilitating communication (e.g. [4]). Thus, in our design prototype specification, the alternative ways of engaging in a routine being presented to children via the wheel spin game, are represented with visuals that can be tailored individually for each child.

The core practical features discussed above can be implemented via a digital medium, which is in keeping with the design requirement pertaining to the use of technology to facilitate access and adaptation to individual needs (6). There is growing evidence for the use of digital interventions within healthcare [13] with some evidence of benefits of game development for NDD populations [43]. In this context, the game-like elements of our intervention are in keeping with the advance in healthcare settings of the application of game-like characteristics - known as "gamification" - to fulfil a nongame objective [10, 23]. Such gamification allows for the bespoke adaptation of implementation rules to meet diverse needs and can therefore facilitate lifestyle integration $[13,25]$. Use of digital technology to implement caregivers' planning of alternative ways of engaging with routines and present these to children with visuals in the context of a structured game, also satisfies the design requirement that flexibility should be imposed in a structured way where possibilities are planned in advance by caregivers and communicated clearly to children (4).

Alongside the core design features discussed above, we identified the need to support management of children's anxiety around flexibility (7), which is in keeping with previously reported links between resistance to change and anxiety [51]. In our design prototype specification, this is implemented via a number of available supported emotion regulation strategies, which may be selected for 
use by the caregiver and child - satisfying the high variability evident in effective emotion regulation strategies across individuals and contexts [7].

We also identified a need for integrated caregiver training and support for problem solving (2), which is in keeping with beneficial effects that have been linked to early intervention approaches in which the main active component is caregiver training [39]. A need for individual problem solving support has been identified during the development of a global-scale parent-training intervention for developmental disorders [44], which was addressed using one-to-one mentoring with a practitioner. Tackling this need within the boundaries of a digital medium therefore presents an important challenge but potentially a new opportunity - the technology can be used to provide prompts in an adaptive way based on a family's prior and ongoing experience.

Finally, we identified a need for clear guidance around structure and flexibility (1) that is in keeping with the dilemma discussed in the Introduction: the high levels of structure recommended as best practice for resistance to change, pitted against the practical challenges of such structure for families. Given that inconsistent or perceived inadequate advice from professionals may be linked with parents' feelings of guilt [9], such clear guidance is crucial and supports the need to develop the presently designed intervention.

\section{Limitations}

We collaborated with caregivers to generate knowledge about the psycho-social context of our proposed early intervention, with which design requirements could be constructed that would optimise likely acceptability and feasibility. Half of the parents involved in the research had a profession indicating high socioeconomic status (see Methods), which is consistent with the expected biases that operate when recruiting for research studies via parent support associations. This must be recognised as an important limitation, since there may be an overrepresentation of experiences linked to higher socioeconomic status in our sample. However, an advantage of the Human-Centred Design-informed approach to analysis taken, is that even views expressed by a minority of participants were considered fully in the generation of design requirements. Thus, to at least some extent, our approach should be robust to sample biases. Nevertheless, future work examining the present design requirements in collaboration with families from underrepresented and/or minority background will be important for tailoring the intervention design to ensure that as wide a range of family characteristics as possible are accommodated.

As outlined in the Analysis section, as an intervention development team, we applied a specific combination of expertise and prior experience to our interpretation of the knowledge produced and how this was applied to the development of design requirements and further design prototype specification. Whilst our team is interdisciplinary, which has been recognised as an advantage for complex intervention development [38], it is likely that a team with a different interdisciplinary make-up would have derived a different design prototype specification. It will therefore be essential in future research to further develop our design prototype in collaboration with a wide range of stakeholders. Furthermore, in this initial examination of psycho-social context, we did not seek to involve children directly. This decision was based on the young age of children who we hope to engage with the intervention and so limited capacity to reflect on relevant issues in an abstract way. It will be important in the future development work to integrate opportunities to support children to contribute to the design process.

\section{Conclusions}

To meet design requirements identified in collaboration with caregivers of children at risk of developing resistance to change, we have specified core features of an intervention aiming to strike a balance between structure and flexibility in children's routines. These include a digital game-based core with individually tailored visuals, which allows caregivers to control the level of flexibility in routines, whilst children feel like they have control and are supported in choice making. Additional components support problem solving for caregivers and emotion regulation for children. Further development through iterative co-design will be important in establishing acceptability and feasibility of the current design in line with the special requirements of families of children with NDDs [47].

\section{Abbreviations}

PWS: Prader-Willi syndrome; FXS: Fragile X syndrome; ASD: Autism spectrum disorder

\section{Supplementary Information}

The online version contains supplementary material available at https://doi. org/10.1186/s12888-021-03519-1.

\section{Additional file 1}

\section{Acknowledgments}

We thank the Medical Research Council for funding this work, the organisations who supported recruitment and provided a platform for dissemination, and the families and professionals who shared their experiences. We would also like to thank the members of the Kate Woodcock Research Group who assisted, most largely: Sweedal Alberts, Alisa Da Palma, Hanan Mohamed, Suhanya Navaratnam, Maria Raza, and Sibghatullah Sohail.

\section{Authors' contributions}

All authors were involved in the design of the study. SB collected the data and was involved in analysis of results and writing of the manuscript. AZ and 
KW were involved in the analysis of results and writing of the manuscript. SM and GS were involved in the writing of the manuscript. The author(s) read and approved the final manuscript.

\section{Funding}

The work was funded by the Medical Research Council UK (Ref: MR/ R000883/1). The MRC approved funding of the research based on a research proposal led by the final author, in collaboration with the third and fourth authors. There was no further input from the funding body in the research.

\section{Availability of data and materials}

The datasets generated during the study are not publicly available due to the sensitive nature of audio recordings. However anonymised transcripts of sections of recordings as required for others' planned research are available upon request.

\section{Declarations}

\section{Ethics approval and consent to participate}

Ethical approval was obtained from the University of Birmingham Ethical Review Committee (ERN 17-0923, 09/01/2018) and written informed consent was provided by all research participants.

\section{Consent for publication}

Not applicable

\section{Competing interests}

The authors declare that they have no competing interests.

\section{Author details}

${ }^{1}$ Centre for Applied Psychology, School of Psychology \& Institute for Mental Health, University of Birmingham, 52 Pritchatts Road, Edgbaston, Birmingham B15 2SA, UK. '2Department of Experimental Psychology, University of Oxford, Oxford, UK. ${ }^{3}$ School of Social Sciences, Education and Social Work, Queen's University Belfast, Belfast, UK.

\section{Received: 16 February 2021 Accepted: 4 October 2021}

\section{Published online: 11 December 2021}

\section{References}

1. Bagatell N. The routines and occupations of families with adolescents with autism spectrum disorders. Focus Autism Other Dev Disord. 2016;31(1):4959. https://doi.org/10.1177/1088357615587503.

2. Barker JE, Semenov AD, Michaelson L, Provan LS, Snyder HR, Munakata Y. Less-structured time in children's daily lives predicts self-directed executive functioning. Front Psychol. 2014;5:593. https://doi.org/10.3389/fpsyg.2014. 00593.

3. Barton E, Fettig A. Parent-implemented interventions for young children with disabilities: a review of fidelity features. J Early Interv. 2013;35(2):194219. https://doi.org/10.1177/1053815113504625.

4. Bull LE, Oliver C, Callaghan E, Woodcock KA. Increased exposure to rigid routines can lead to increased challenging behavior following changes to those routines. J Autism Dev Disord. 2015a;45(6):1569-78. https://doi.org/1 0.1007/s10803-014-2308-2.

5. Bull LE, Oliver C, Woodcock KA. Signalling changes to individuals who show resistance to change can reduce challenging behaviour. Behav Ther Exp Psychiatry. 2017;54:58-70. https://doi.org/10.1016/j.jbtep.2016.06.006

6. Bull LE, Oliver C, Tunnicliffe PL, Woodcock KA. Increased exposure to rigid routines can lead to increased challenging behaviours following changes to those routines. J Autism Dev Disord. 2015b;45(6):1569-78. https://doi.org/1 0.1007/s10803-014-2308-2.

7. Cibralic S, Kohlhoff J, Wallace N, McMahon C, Eapen V. A systematic review of emotion regulation in children with autism spectrum disorder. Res Autism Spectr Disord. 2019;68:21. https://doi.org/10.1016/j.rasd.2019.101422.

8. Cohen J. Weighted kappa: nominal scale agreement with provision for scaled disagreement or partial credit. Psychol Bull. 1968;70(4):213-20. https://doi.org/10.1037/h0026256.

9. Dauman N, Haza M, Erlandsson S. Liberating parents from guilt: a grounded theory study of parents' internet communities for the recognition of ADHD. Int J Qual Stud Health Well Being. 2019;14(1):12. https://doi.org/10.1080/174 82631.2018.1564520.
10. Deterding $\mathrm{S}$. The lens of intrinsic skill atoms: a method for gameful design. Hum Comput Interact. 2015;30(304):294-335. https://doi.org/10.1080/073 70024.2014.993471.

11. DeVane BM, Dietmeier J, Missall K, Nanda S, Cox M, Miller BJ, et al. Dropping in to game designlterations of a skatepark physics game for achildren's museum exhibit. Inf Learn Sci. 2019;120(9/10):663-78. https://doi.org/10.11 08/ILS-03-2019-0023.

12. Elo $S$, Kyngas $H$. The qualitative content analysis process. J Adv Nurs. 2007: 62(1):107-15. https://doi.org/10.1111/j.1365-2648.2007.04569.x.

13. Fleming T, Bavin L, Lucassen M, Stasiak K, Hopkins S, Mery S. Beyond the trial: systematic review of real-world uptake and engagement with digital self-help interventions for depression, low mood, or anxiety. J Med Internet Res. 2018;20(6):e19. https://doi.org/10.2196/jmir.9275.

14. Gioia GA, Isquith PK, Guy SC, Kenworthy L. Behaviour rating inventory of executive function. Odessa: Psychological Assessment Resources; 2000.

15. Glasgow RE, Vogt TM, Boles SM. Evaluating the public health impact of health promotion interventions: the RE-AIM framework. Am J Public Health. 1999:89(9):1322-7 https://doi.org/10.2105/ajph.89.9.1322.

16. Goodman R. The strengths and difficulties questionnaire: a research note. J Child Psychol Psychiatry. 1997;38(5):581-6. https://doi.org/10.1111/j.1469-761 0.1997.tb01545.x.

17. Green VA, Sigafoos J, Pituch K, Itchon J, O'Reilly M, Lancioni GE. Assessing behavioral flexibility in individuals with developmental disabilities. Focus Autism Other Dev Disabil. 2006;21(4):230-6 https://doi.org/10.1177/10883 576060210040401.

18. Greenberg JS, Seltzer MM, Hong J, Orsmond Gl. Bidirectional effects of expressed emotion and behavior problems and symptoms in adolescents and adults with autism. Am J Ment Retard. 2006;111(4):229-49. https://doi. org/10.1352/0895-8017(2006)111[229:BEOEEA]2.0.CO;2.

19. Haig EL, Woodcock KA. Rigidity in routines and the development of resistance to change in individuals with Prader-Willi syndrome. J Intellect Disabil Res. 2017;61(5):488-500. https://doi.org/10.1111/jir.12368.

20. Hamdani SU, Akhtar P, Huma Z, Nazir H, Minhas FA, Sikander S, et al. WHO parents skills training (PST) programme for children with developmental disorders and delaysdelivered by family volunteers in rural Pakistan: study protocol for effectiveness implementation hybrid cluster randomized controlled trial. Glob Ment Health. 2017:4:1-11. https://doi.org/10.1017/ gmh.2017.7.

21. Harrop C. Evidence-based, parent-mediated interventions for young children with autism spectrum disorder: the case of restricted and repetitive behaviors. Autism. 2015;19(6):662-72. https://doi.org/10.1177/136236131454 5685.

22. Harrop C, McBee M, Boyd BA. How are child restricted and repetitive behaviors associated withcaregiver stress over time? A parallel process multilevel growth model. J Autism Dev Disord. 2016;46(5):1773-83. https:// doi.org/10.1007/s10803-016-2707-7.

23. King D, Greaves F, Exeter C, Darzi A. 'Gamification': influencing health behaviours with games. J R Soc Med. 2013;106(3):76-8. https://doi.org/10.11 77/0141076813480996.

24. Knight V, Sartini E, Spriggs AD. Evaluating visual activity schedules as evidence-based practice forindividuals with autism spectrum disorders. J Autism Dev Disord. 2015;45(1). https://doi.org/10.1007/s1 0803-014-2201-z.

25. Larson E. Caregiving and autism: how does children's propensity for routinization influence participation in family activities. Occup Ther J Res. 2006;26(2):69-79. https://doi.org/10.1177/153944920602600205.

26. Lowes L, Robling MR, Bennert K, Crawley C, Hambly H, Hawthorne K, et al. Involving lay and professional stakeholders in the development of a research intervention for the DEPICTED study. Health Expect. 2011;14(3): 250-60. https://doi.org/10.1111/j.1369-7625.2010.00625.x.

27. Macdonald L, Trembath D, Ashburner J, Costley D, Keen D. The use of visual schedules and work systems to increase the on-task behaviour of students on the autism spectrum in mainstream classrooms. J Res Spec Educ Needs. 2018;18(4):254-66. https://doi. org/10.1111/1471-3802.12409.

28. Macleod MR, Michie S, Roberts I, Dirnagl U, Chalmers I, loannidis JP, et al. Biomedical research: increasing value, reducing waste. Lancet (London, England). 2014;383(9912):101-4 https://doi.org/10.1016/S01406736(13)62329-6.

29. McHugh ML. Interrater reliability: the kappa statistic. Biochem Med. 2012; 22(3):276-82. ISSN: 1330-0962. https://doi.org/10.11613/BM.2012.031. 
30. Mesibov GB, Shea $V$. The TEACCH program in the era of evidence-based practice. J Autism Dev Disord. 2010;40(5):570-9. https://doi.org/10.1007/s1 0803-009-0901-6.

31. Miller HL, Ragozzino ME, Cook EH, Sweeney JA, Mosconi MW. Cognitive set shifting deficits and their relationship to repetitive behaviors in autism spectrum disorder. J Autism Dev Disord. 2015;45(3):805-15. https://doi.org/1 0.1007/s10803-014-2244-1.

32. Miodrag N, Hodapp RM. Chronic stress and health among parents of children with intellectual anddevelopmental disabilities. Curr Opin Psychiatry. 2010; 23(5):407-11. https://doi.org/10.1097/YCO.0b013e32833a8796.

33. Moss J, Oliver C, Arron K, Burbidge C, Berg K. The prevalence and phenomenology of repetitivebehavior in genetic syndromes. J Autism Dev Disord. 2009;39(4):572e588. https://doi.org/10.1007/s10803-008-0655-6.

34. Nadig A, Lee I, Singh L, Bosshart K, Ozonoff S. How does the topic of conversation affect verbal exchange and eye gaze? Acomparison between typical development and high-functioning autism. Neuropsychologia. 2010; 48(9):2730-9. https://doi.org/10.1016/j.neuropsychologia.2010.05.020.

35. National Institute for Health and Care Excellence. Autism: the management and support of children and young people on the autism spectrum. CG 170. London: National Institute for Health and Care Excellence; 2013.

36. O'Brien B, Harris I, Beckman T, Reed D, Cook D. Standards for reporting qualitative research. Acad Med. 2014;89(9):1245-51. https://doi.org/10.1097/a cm.0000000000000388.

37. O'Cathain A, Croot L, Duncan E, Rousseau N, Sworn K, Turner KM, et al. Guidance on how to develop complex interventions to improve health and healthcare. BMJ Open. 2019a;9(8):e029954. https://doi.org/10.1136/ bmjopen-2019-029954

38. O'Cathain A, Croot L, Sworn K, Duncan E, Rousseau N, Turner K, et al. Taxonomy of approaches to developing interventions to improve health: a systematic methods overview. Pilot Feasibility Stud. 2019b;5(1):41. https:// doi.org/10.1186/s40814019-0425-6.

39. Oono IP, Honey EJ, McConachie H. Parent-mediated early intervention for young children with autism spectrum disorders (ASD). Evid Based Child Health. 2013;8(6):2380-479. https://doi.org/10.1002/ebch.1952.

40. Pierce K, Courchesne E. Evidence for a cerebellar role in reduced exploration and stereotyped behavior in autism. Biol Psychiatry. 2001;49:655-64. https:// doi.org/10.1016/S0006-3223(00)01008-8.

41. Powell D, Dunlap G. Family-focused interventions for promoting socialemotional development in infants and toddlers with or at risk for disabilities. Roadmap to effective intervention practices \#5. In: Technical assistance center on social emotional intervention for young children. Tampa: University of South Florida; 2010.

42. Rice LJ, Woodcock KA, Einfeld SL. The characteristics of temper outbursts in Prader-Willi syndrome. Am J Med Genet A. 2018;20(18):1-10. https://doi. org/10.1002/ajmg.a.40480.

43. Robb N, Waller A, Woodcock KA. Developing a task switching training game for children with a rare genetic syndrome linked to intellectual disability. Simul Gaming. 2019;50(2):160-79. https://doi.org/10.1177/1046878119834319.

44. Salomone E, Pacione L, Shire S, Brown FL, Reichow B, Servili C. Development of the WHO caregiver skills training program for developmental disorders or delays. Front Psychiatry. 2019;10:9. https://doi. org/10.3389/fpsyt.2019.00769.

45. Smith T, ladarola S, Mandell DS, Harwood R, Kasari C. Community-partnered research with urban school districts that serve children with autism spectrum disorder. Acad Pediatr. 2017;17(6):614-9. https://doi.org/10.1016/j.a cap.2017.04.017

46. Strain PS, Bovey EH. Randomized, controlled trial of the LEAP model of early intervention for young children with autism spectrum disorders. Top Early Child Spec Educ. 2011;31(3):133-54. https://doi.org/10.1177/02711214114 08740.

47. Thabrew H, Fleming T, Hetrick S, Merry S. Co-design of eHealth interventions with children and young people. Front Psychol. 2018;9(481). https://doi.org/10.3389/fpsyt.2018.00481.

48. The National Statistics Socio-economic classification (NS-SEC): new Standard Occupational Classification (SOC2000). 2016. Retrieved from https://www. ons.gov.uk/methodology/classificationsandstandards/otherclassifications/ thenationalstatisticssocioeconomicclassificationnssecrebasedonsoc2010.

49. Woodcock KA, Blackwell S. Psychological treatment strategies for challenging behaviours in neurodevelopmental disorders: what lies beyond a purely behavioural approach? Curr Opin Psychiatry. 2020;33(2):92-109. https://doi.org/10.1097/yco.0000000000000571.
50. Woodcock KA, Cheung C, González Marx D, Mandy W. Social decision making in autistic adolescents: the role of theory of mind, executive functioning and emotion regulation. J Autism Dev Disord. 2019;50(7):250112. https://doi.org/10.1007/s10803-019-03975-5.

51. Woodcock K, Oliver C, Humphreys G. Associations between repetitive questioning, resistance tochange, temper outbursts and anxiety in PraderWilli and Fragile-X syndromes. J Intellect Disabil Res. 2009a;53(3):265-78. https://doi.org/10.1111/j.1365-2788.2008.01122.x.

52. Woodcock KA, Oliver C, Humphreys GW. Task-switching deficits and repetitive behaviour in genetic neurodevelopmental disorders: data from children with Prader-Willi syndrome chromosome 15 q11-q13 deletion and boys with fragile $X$ syndrome. Cogn Neuropsychol. 2009b;26(2):172-94. https://doi.org/10.1080/02643290802685921.

53. Woodcock KA, Oliver C, Humphreys GW. A specific pathway can be identified between geneticcharacteristics and behaviour profiles in PraderWilli syndrome via cognitive, environmental andphysiological mechanisms. J Intellect Disabil Res. 2009c;53(6):493-500. https://doi.org/10.1111/j.1365-2 788.2009.01167.x.

54. Yardley L, Morrison L, Bradbury K, Muller I. The person-based approach to intervention development: application to digital health-related behavior change interventions. J Med Internet Res. 2015;17(1):e30. https://doi.org/1 0.2196/jmir.4055.

\section{Publisher's Note}

Springer Nature remains neutral with regard to jurisdictional claims in published maps and institutional affiliations.
Ready to submit your research? Choose BMC and benefit from:

- fast, convenient online submission

- thorough peer review by experienced researchers in your field

- rapid publication on acceptance

- support for research data, including large and complex data types

- gold Open Access which fosters wider collaboration and increased citations

- maximum visibility for your research: over $100 \mathrm{M}$ website views per year

At $\mathrm{BMC}$, research is always in progress.

Learn more biomedcentral.com/submissions 